\title{
LIPID PROFILE IN CURRENT SMOKERS WITH COPD
}

\author{
Dasari Nishanth Vundela1 ${ }^{1}$ B. Goutam², K. Sailaja ${ }^{3}$ \\ ${ }^{1}$ Senior Resident, Department of Pulmonary Medicine, Mediciti Institute of Medical Sciences, Ghanpur. \\ ${ }^{2}$ Senior Resident, Department of Pulmonary Medicine, Mediciti Institute of Medical Sciences, Ghanpur. \\ ${ }^{3}$ Professor, Department of Pulmonary Medicine, Mediciti Institute of Medical Sciences, Ghanpur.
}

\section{ABSTRACT}

\section{BACKGROUND}

Atherogenic lipid profile is one of the most important co-morbidities related to COPD. Patients with Atherogenic blood lipid profile are more prone to develop atherosclerosis and subsequently leading to CVD. Lung cancer and cardiovascular complications accounted for nearly two-thirds of all deaths during follow-up of a cohort of mild COPD patients in the Lung Health Study.

The aim of this study is to analyse the effect of current smokers of COPD on Lipid Profile.

\section{MATERIALS AND METHODS}

Subjects of age 40 years and older attending and admitted under the Dept. of Pulmonology, Mediciti Hospitals, Hyderabad are included in the analysis. The subjects will be evaluated on the basis of a questionnaire to assess their Lipid profile and COPD status. The COPD severity will be determined by pulmonary function testing. The patients included will be assessed up to the point of study and progress will be recorded as per the total duration of the study.

\section{RESULTS}

Total number of patients studied (n): 64. Mean age of the patients was 63.76 years. In study population, all COPD patients have low HDL cholesterol with increasing severity of COPD, HDL cholesterol levels are found to be decreasing. All patients have Total cholesterol (CH), triglycerides (TG) and LDL cholesterol within normal limits and their variation with severity of COPD is statistically insignificant.

\section{CONCLUSION}

Smoking is an important risk factor for COPD as well as dyslipidaemia. There was no significant correlation between severity of airflow obstruction and dyslipidaemia. Severity of COPD does not have correlation with Lipid changes, but all COPD patients have low levels of HDL.

\section{KEYWORDS}

COPD, Lipid Profile, HDL, LDL, Dyslipidaemia, Smokers.

HOW TO CITE THIS ARTICLE: Vundela DN, Goutam B, Sailaja K. Lipid profile in current smokers with COPD. J. Evolution Med. Dent. Sci. 2017;6(62):4529-4533, DOI: 10.14260/Jemds/2017/980

\section{BACKGROUND}

Chronic Obstructive Pulmonary Disease (COPD) is a common preventable and treatable disease that is characterised by persistent respiratory symptoms and airflow limitation that is due to airway and/or alveolar abnormalities usually caused by significant exposure to noxious particles or gases. ${ }^{1}$ Various anatomic lesions can cause the airflow limitation. Finally, the clinical features result not only from the airflow limitation but also from other features, both within the lung (e.g. cough and sputum production) and systemically. ${ }^{2}$ COPD affects approximately $5 \%$ of adults in India. It is more common among men than women. Surveys done by the Indian Council of Medical Research in 2006 among residents of Chandigarh, Delhi, Bangalore and Kanpur reflect that the prevalence is increasing, largely due to an increase in smoking and air pollution in rapidly urbanising and developing societies. Its incidence was expected to double in the world between 1990

Financial or Other, Competing Interest: None.

Submission 21-06-2017, Peer Review 21-07-2017,

Acceptance 27-07-2017, Published 03-08-2017.

Corresponding Author:

Dr. Dasari Nishanth Vundela,

8-2-693/2/26\&27, Road No. 12,

Mithilanagar Colony, Banjara Hills,

Hyderabad-500034.

E-mail: d.nishanth.v@gmail.com

DOI: $10.14260 /$ jemds $/ 2017 / 980$ (c) $(i) \$$ and 2020, according to the Global Initiative for Obstructive Lung Disease (GOLD). By 2020, COPD is expected to become the third major cause of death. The cost of COPD to the country as well as to the individual is enormous. ${ }^{3,4,5}$ COPD can no longer be considered a disease only of the lungs. It is associated with a wide variety of systemic consequences, most notably systemic inflammation. ${ }^{6}$ The association between COPD and atherosclerosis is a cause for concern as the actual burden of disease due to the former would get amplified many-fold, as the available epidemiological evidence suggests COPD is a risk factor for atherosclerosis. The link between the two may be a coincidence as both occur with increasing frequency, as the age increases and both are very common disease states. The link also underlines the commonality of a strong risk factor, i.e. smoking between the two. However, the link may also be biological. Increasingly, it is becoming apparent that the two may share common pathways in pathogenesis. The hypothesis is that inflammation underlies the pathogenesis of both these conditions and there are common mediators involved. Chronic obstructive pulmonary disease is usually related to history of tobacco smoking. The free radicals in the tobacco smoke and the free radicals produced by metabolism of other components may be responsible for the tissue damage seen in chronic obstructive pulmonary disease. Smoking affects the lipid profile of COPD patients. Increased carbon monoxide in the blood of cigarette smokers may damage the 
endothelium and accelerate the entry of cholesterol into the wall of the artery. ${ }^{7}$ A large number of risk factor, which predispose to atherosclerosis and hence Coronary Heart Disease (CAD) have been identified. These include modifiable ones like hypertension, dyslipidaemia, smoking, diabetes mellitus, changing lifestyle and non-modifiable ones like age and sex. As the number of risk factors in an individual increase, so does the risk of developing atherosclerosis and its complication, mainly Coronary Artery Disease (CAD). In subject with more than one of these risk factors, the risk is more than additive. ${ }^{8}$ An additional mechanism has been recently suggested that smoking adversely affect the concentration of the plasma lipids and lipoproteins. However, studies to date have revealed incomplete, inconclusive or conflicting results about the association of smoking on the plasma lipid and lipoprotein levels. In some studies smokers had increased plasma cholesterol and in others plasma cholesterol level have actually been lower. Only a few studies have specifically examined the plasma lipoprotein according to smoking status or number of cigarettes smoked (Dosage).

Smokers are reported to have higher Low-Density Lipoprotein (LDL) and lower high-density cholesterol levels than non-smokers. Finally, conflicting data on plasma triglyceride levels in smokers have been reported.

In this study, an effort is made to establish correlation between severity of COPD, smoking with changes in lipid profile in patients with COPD.

\section{MATERIALS AND METHODS}

The present study entitled "Lipid Profile in Current Smokers with COPD" was undertaken at Mediciti Institute of Medical Sciences, Ghanpur. It is an institutional based descriptive study at Department of Pulmonary Medicine for a duration of 2 years from September 2013 to October 2015. The study group consists of 64 subjects presenting to Mediciti Hospital OPD/ IP pulmonary services. All the subjects were interviewed and complete history was taken along with thorough clinical examination was done according to proforma that was predesigned. Informed consent was secured from the patients for participation in the study. Patients were investigated when their condition stabilised before they were discharged. Spirometry (pre- and postbronchodilator), lipid profile analysis, chest X-ray PA view, ECG, haemogram and other routine investigations were done.

\section{Inclusion Criteria}

Stable current smokers with COPD without any acute infective exacerbation within 3 months of enrolment for the study using 2015 GOLD Guidelines.

\section{Exclusion Criteria}

1. Uncooperative, unwilling patients to divulge disease details.

2. Patients with pre-existing structural lung diseases, lung cancer and critically ill.

3. Episodes of previous pulmonary embolism, metabolic acidosis, immunological disease, cancer, history of venous or arterial thrombosis, hypertension, atherosclerotic vascular disease, diabetes mellitus or renal disease.

\section{Data Collection}

The study group consists of 64 subjects presenting to Mediciti Hospital OPD/ IP pulmonary services. All the subjects were interviewed and complete history was taken along with thorough clinical examination was done according to proforma that was predesigned. Informed consent was secured from the patients for participation in the study. Patients were investigated when their condition stabilised before they were discharged. Spirometry (pre- and postbronchodilator), lipid profile analysis, chest X-ray PA view, ECG, haemogram and other routine investigations were done.

\section{Statistical Analysis}

Statistical data analysis was done using Microsoft Excel 2007, SPSS (Statistical Package for Social Science) version 15. Mean, standard deviation is calculated for age, height, weight, Body Mass Index (BMI), FEV $1, \mathrm{FVC}, \mathrm{FEV}_{1} \%$. The study population was divided into 4 groups, while stage 1 - 4 COPD were assigned groups 1 to 4 respectively.

For intragroup variable analysis mean and standard deviations were calculated. The mean differences were compared by T-tests/ ANOVA, whichever is feasible. ANOVA test was applied for assessing the strength of association and trends in between the various study variables. Values with probability $<0.05$ were considered to be statistically significant.

\section{RESULTS}

The present study entitled "Lipid Profile in Current Smokers with COPD" was conducted in the Department of Pulmonology, Mediciti Institute of Medical Sciences, Ghanpur. Total number of patients studied (n): 64 .

\section{The following are our Observations Age Distribution}

In our study, majority of the patients were above 60 years. $65.62 \%(n=42)$ were in the age group $61-80$, followed by $34.38 \%(n=22)$ patients in age group $41-60$. No patients were present over 80 years of age.

Mean age of the patients was 63.76 years.

\section{Sex Distribution}

In our study, all the patients were males.

\section{Body Mass Index (BMI)}

In our study majority of the patients, i.e. $43.75 \%$ had normal BMI at the time of presentation, $23.44 \%$ were overweight and a $15.62 \%$ of them were obese and $17.19 \%$ of them underweight. An average BMI was $23.48 \pm 4.91$ in all patients.

\section{COPD Staging}

\begin{tabular}{|c|c|c|}
\hline Stage & No. of Patients (n= 64) & $\mathbf{\%}$ \\
\hline I & 0 & 0 \\
\hline II & 22 & 34.37 \\
\hline III & 27 & 42.19 \\
\hline IV & 15 & 23.44 \\
\hline \multicolumn{2}{|c|}{ Table 1 } \\
\hline
\end{tabular}

In our study, majority of patients $42.19 \%(n=27)$ are in Severe COPD (III) group followed by Moderate COPD (II) $34.37 \%(n=22)$ and $23.44 \%(n=15)$ are in Very Severe COPD (IV) group. 


\section{Smoking Habits}

In the present study $15.63 \%$ were mild smokers with Smoking Index of less than 10 pack years, 57.81\% were moderate smokers with Smoking Index between 10 - 20 pack years and $26.56 \%$ were heavy smokers with Smoking Index more than 20 pack years. The average pack years is $17.19 \pm$ 10.27 .

COPD and BMI

\begin{tabular}{|c|c|}
\hline COPD Stage & BMI (Mean) \\
\hline Moderate & $25.29 \pm 4.6$ \\
\hline Severe & $22.46 \pm 4.5$ \\
\hline Very Severe & $22.69 \pm 5.5$ \\
\hline \multicolumn{2}{|c|}{ Table 2 } \\
\hline
\end{tabular}

The BMI was found to be decreasing with severity of COPD stage, but ANOVA analysis is statistically not significant $(\mathrm{P}=0.103)$ between BMI and severity of the COPD.

\section{COPD and Smoking Status}

\begin{tabular}{|c|c|}
\hline COPD Stage & Smoking P'yrs (mean) \\
\hline Moderate & $12.95 \pm 7.39$ \\
\hline Severe & $20.44 \pm 11.45$ \\
\hline Very Severe & $17.53 \pm 10.02$ \\
\hline \multicolumn{2}{|c|}{ Table 3 } \\
\hline
\end{tabular}

In our study with increased smoking in terms of pack years, severity of COPD also increases.

Patients with severe COPD (III) have higher number of PYS; it may be due to larger number of patients in stage III of COPD (27) than stage IV of COPD.(9)

ANOVA analysis is statistically significant $(\mathrm{P}=0.037)$ between smoking and severity of the COPD.

\section{COPD and Lipids}

\begin{tabular}{|c|c|c|c|c|}
\hline $\begin{array}{c}\text { [mg/dL] } \\
\text { (mean) }\end{array}$ & $\begin{array}{c}\text { Moderate } \\
\text { COPD (n= 22) }\end{array}$ & $\begin{array}{c}\text { Severe } \\
\text { COPD (n= } \\
\mathbf{2 7})\end{array}$ & $\begin{array}{c}\text { Very Severe } \\
\text { COPD (n= 15) }\end{array}$ & $\mathbf{P}$ \\
\hline CH & $\begin{array}{c}171.86 \pm \\
48.83\end{array}$ & $\begin{array}{c}173.18 \pm \\
35.48\end{array}$ & $157.3 \pm 30.23$ & 0.419 \\
\hline TG & $97.45 \pm 39.67$ & $96.48 \pm 42.49$ & $92.40 \pm 27.36$ & 0.921 \\
\hline LDL & $102.23 \pm 36.4$ & $94.74 \pm 26.48$ & $91.07 \pm 16.87$ & 0.473 \\
\hline HDL & $37.95 \pm 8.13$ & $34.44 \pm 7.38$ & $30.4 \pm 6.5$ & 0.014 \\
\hline \multicolumn{5}{|c}{ Table 4 } \\
\hline
\end{tabular}

In study population, all COPD patients have low HDL cholesterol. With increasing of severity of COPD, HDL cholesterol levels are found to be decreasing. All patients have Total cholesterol (CH), triglycerides (TG) and LDL cholesterol within normal limits and their variation with severity of COPD is statistically insignificant.

LDL/ HDL Ratio and COPD

\begin{tabular}{|c|c|c|c|}
\hline \multicolumn{4}{|c|}{ LDL/ HDL Ratio } \\
\hline COPD Stage & $\begin{array}{c}\text { Moderate } \\
\text { COPD } \\
\text { (n= 22) }\end{array}$ & $\begin{array}{c}\text { Severe } \\
\text { COPD } \\
\text { (n= 27) }\end{array}$ & $\begin{array}{c}\text { Very Severe } \\
\text { COPD } \\
\text { (n= 15) }\end{array}$ \\
\hline $\begin{array}{c}\text { Minimum } \\
(\mathrm{mg} / \mathrm{dL})\end{array}$ & 0.71 & 1.23 & 1.25 \\
\hline $\begin{array}{c}\text { Maximum } \\
(\mathrm{mg} / \mathrm{dL})\end{array}$ & 4.78 & 4.76 & 5.45 \\
\hline \multicolumn{4}{|c|}{ Table 5 } \\
\hline
\end{tabular}

\begin{tabular}{|c|c|c|c|c|}
\hline $\begin{array}{c}\text { COPD } \\
\text { Staging }\end{array}$ & $\begin{array}{c}\text { Moderate } \\
(\mathbf{n = 2 2})\end{array}$ & $\begin{array}{c}\text { Severe } \\
(\mathbf{n = 2 7})\end{array}$ & $\begin{array}{c}\text { Very Severe } \\
(\mathbf{n = 1 5})\end{array}$ & $\mathbf{P}$ \\
\hline $\begin{array}{c}\text { LDL/ HDL } \\
\text { (mean) }\end{array}$ & $2.74 \pm 0.90$ & $2.78 \pm 0.69$ & $3.09 \pm 1.21$ & 0.477 \\
\hline
\end{tabular}

As depicted in the above table the mean values of LDL/ HDL are increasing with severity of COPD, which indicates the atherogenic risk.

However, statistical significance could not be established $(\mathrm{p}=0.477)$.

\section{TC/ HDL Ratio and COPD}

\begin{tabular}{|c|c|c|c|c|}
\hline & \multicolumn{3}{|c|}{ COPD Staging } & \multirow{2}{*}{} \\
\cline { 2 - 4 } & $\begin{array}{c}\text { Moderate } \\
(\mathbf{n = 2 2})\end{array}$ & $\begin{array}{c}\text { Severe } \\
(\mathbf{n = 2 7})\end{array}$ & $\begin{array}{c}\text { Very Severe } \\
(\mathbf{n = 1 5})\end{array}$ & $\mathbf{P}$ \\
\hline $\begin{array}{c}\text { TC/ HDL } \\
\text { (mean) }\end{array}$ & $4.5 \pm 1.16$ & $5.17 \pm 1.25$ & $5.46 \pm 1.97$ & 0.166 \\
\hline \multicolumn{4}{|c|}{ Table 6 } \\
\hline
\end{tabular}

As depicted in the above table the mean values of TC/ HDL are increasing with severity of COPD, which indicates the atherogenic risk.

However, statistical significance could not be established $(\mathrm{p}=0.166)$.

Comparison of Lipid profile with smoking status reveals-

Smoking Status and Lipids

\begin{tabular}{|c|c|c|c|c|}
\hline $\begin{array}{c}\text { Mean } \\
{[\mathbf{m g} / \mathbf{d L}]}\end{array}$ & $\begin{array}{c}\text { Mild } \\
\text { Smokers } \\
(\mathbf{n = 1 0 )}\end{array}$ & $\begin{array}{c}\text { Moderate } \\
\text { Smokers } \\
(\mathbf{n = 3 7})\end{array}$ & $\begin{array}{c}\text { Heavy } \\
\text { Smokers } \\
(\mathbf{n = 1 7})\end{array}$ & $\mathbf{P}$ \\
\hline CH & $165.3 \pm 50.61$ & $167.81 \pm 36.55$ & $173.64 \pm 40.81$ & 0.841 \\
\hline TG & $128.1 \pm 60.78$ & $93.65 \pm 29.8$ & $81.70 \pm 26.86$ & 0.006 \\
\hline LDL & $91.5 \pm 46.85$ & $96.76 \pm 24.85$ & $98.71 \pm 23.86$ & 0.819 \\
\hline HDL & $40.4 \pm 8.9$ & $34.6 \pm 7.7$ & $31.4 \pm 5.85$ & 0.014 \\
\hline \multicolumn{5}{|c|}{ Table 7 } \\
\hline
\end{tabular}

In our study with increasing of smoking HDL levels are decreasing and heavy smokers have low levels of HDL cholesterol when compared to other groups.

Smoking effect on HDL levels are statistically significant $(\mathrm{p}=0.014)$.

Smoking effect on TG levels are also statistically significant $(p=0.006)$.

LDL/ HDL Ratio, CH/ HDL Ratio in Mild, Moderate and Heavy Smokers

\begin{tabular}{|c|c|c|c|c|}
\hline & $\begin{array}{c}\text { Mild } \\
\text { Smoker } \\
(\mathbf{n = 1 0 )}\end{array}$ & $\begin{array}{c}\text { Moderate } \\
\text { Smokers } \\
(\mathbf{n = 3 7})\end{array}$ & $\begin{array}{c}\text { Heavy } \\
\text { Smoker } \\
(\mathbf{n = 1 7})\end{array}$ & $\mathbf{P}$ \\
\hline LDL/ HDL & $2.33 \pm 1.21$ & $2.81 \pm 0.77$ & $3.21 \pm 0.86$ & 0.045 \\
\hline CH/ HDL & $4.21 \pm 1.38$ & $5.00 \pm 1.42$ & $5.61 \pm 1.32$ & 0.048 \\
\hline \multicolumn{5}{|c}{ Table 8 } \\
\hline \multicolumn{5}{|c}{}
\end{tabular}

LDL/ HDL and CH/ HDL ratios increase as number of pack years (PYS) increases.

LDL/ HDL ratio when compared between mild, moderate and heavy smokers is statistically significant ( $p$ value $=0.045)$ and CH/ HDL ratio when compared between mild, moderate and heavy smokers is also statistically significant ( $\mathrm{p}$ value $=$ 0.048).

High LDL/HDL and TC/HDL ratios in smokers indicate atherogenic effect of smoking. 
Descriptive Analysis

\begin{tabular}{|c|c|c|c|}
\hline Variable & Min. & Max. & Mean \pm SD \\
\hline Age & 46 & 78 & $63.76 \pm 7.72$ \\
\hline BMI $\left[\mathrm{kg} / \mathrm{m}^{2}\right]$ & 14.00 & 32.80 & $23.48 \pm 4.91$ \\
\hline $\begin{array}{c}\mathrm{Sr} . \mathrm{CH} \\
{[\mathrm{mg} / \mathrm{dL}]}\end{array}$ & 63.00 & 252.00 & $168.96 \pm 39.51$ \\
\hline $\begin{array}{c}\mathrm{Sr} . \mathrm{TG} \\
{[\mathrm{mg} / \mathrm{dL}]}\end{array}$ & 49.00 & 250.00 & $95.85 \pm 37.95$ \\
\hline LDL $[\mathrm{mg} / \mathrm{dL}]$ & 30.00 & 196.00 & $96.45 \pm 28.57$ \\
\hline HDL $[\mathrm{mg} / \mathrm{dL}]$ & 20.00 & 60.00 & $34.70 \pm 7.87$ \\
\hline $\mathrm{LDL} / \mathrm{HDL}$ & 0.71 & 5.53 & $2.84 \pm 0.90$ \\
\hline $\mathrm{CH} / \mathrm{HDL}$ & 1.50 & 10.50 & $5.04 \pm 1.44$ \\
\hline \multicolumn{3}{|c|}{ Table 9 } \\
\hline
\end{tabular}

Descriptive analyses of various variables in the study show maximum and minimum value in each category along with mean value.

\section{DISCUSSION}

In a study period of 2 years from 2013 to 2015, a point observation study of Analysis of Lipid Profile in current smokers of COPD patients was conducted in the Department of Pulmonology in Mediciti Institute of Medical Sciences, Ghanpur on stable COPD patients presenting to the OPD for routine followup.

\section{Anthropometric Data \\ Age}

As it is well known that COPD is the disease of elderly. In present study, mean age of study population is $63.76 \mathrm{yrs}$. ranging from 46 to 78 years of age which is comparable with other studies.

\section{Sex Distribution}

COPD is a male dominant disease, the high prevalence in males which is due to higher prevalence of smoking in this gender and also males are more susceptible to smoking than females. ${ }^{8}$ However, in the present study there were no female subjects, all the subjects were male.

\section{Comparison of Body Mass Index}

Most of the patients were in the normal BMI of $23.48 \mathrm{~kg} / \mathrm{m}^{2}$.

\section{Stage Wise Comparison of BMI}

Analysis of Body Mass Index demonstrated a decreased trend with increasing of COPD severity, as moderate COPD patients showed normal BMI and severe, very severe COPD patients showed low BMI. These values are comparable with other study by $\operatorname{Sin}$ et $a l, 10$ but in contrast in our study ANOVA analysis is not statistically significant $(\mathrm{p}=0.103)$ between BMI and severity of COPD.

\section{Prevalence of Smokers}

Study population comprised of predominantly smokers $(100 \%)$. In the present study, most of the patients were smokers, which are comparable with other study groups. In our study, there were no female COPD patients.
Stage Wise Comparison of Smoking Reveals

\begin{tabular}{|c|c|c|}
\hline \multirow{2}{*}{ Gold Stage } & \multicolumn{2}{|c|}{ Smoking } \\
\cline { 2 - 3 } & Sin et al(10) & Present Study \\
\hline Moderate & $7.08 \pm 7.2$ & $12.95 \pm 7.39$ \\
\hline Severe & $8.24 \pm 5.2$ & $20.44 \pm 11.45$ \\
\hline Very Severe & $7.69 \pm 6.7$ & $17.53 \pm 10.02$ \\
\hline \multicolumn{2}{|c|}{ Table 10 } \\
\hline
\end{tabular}

Smoking is very important risk factor for COPD seen in $85 \%$ of the patients who develop COPD. In our study population with increasing severity of smoking, COPD severity is also increasing. This is statistically significant $(\mathrm{p}=$ 0.037).

\section{Lipid Profile}

Fasting lipid profiles of the study group revealed normolipidaemia in the majority of cases, but with increasing of severity of COPD patients showed dyslipidaemia in the form of low HDL levels. In our study group, all the patients had total cholesterol, triglycerides, LDL (mean) within normal limits which is comparable to other studies. Mean LDL levels are mildly elevated in all other studies in comparison to our study, but the study population had low levels of mean HDL in contrast to other studies.

\section{Stage Wise comparison of the Lipid Profile reveals COPD Vs Total Serum Cholesterol}

Sin and Man et al in the Third Health and Nutrition Examination Survey demonstrated that with severe airflow obstruction had slightly higher serum concentrations total cholesterol.10 Canan Radavus et al demonstrated total cholesterol decreasing with increasing of severity of COPD.11

In our study, total cholesterol levels are within normal levels irrespective of severity of COPD.

\section{COPD Vs Triglycerides}

Sin and Man et al demonstrated that with severe airflow obstruction had slightly higher serum concentrations of triglycerides in all stages of COPD. ${ }^{11}$ Canan Radavus et al demonstrated triglycerides are decreasing with increasing of severity of COPD. But our study population showed normal levels of Triglycerides irrespective of severity of COPD.

\section{COPD Vs Serum LDL}

Sin and Man et al in the Third Health and Nutrition Examination Survey demonstrated that there were no significant differences in the LDL-C levels in all stages of COPD. ${ }^{10}$ Canan Radavus et al demonstrated LDL-C levels are decreasing with increasing of severity of COPD. ${ }^{11}$

Our study population also showed normal levels of Serum LDL, though compared to other studies serum LDL is on lower range. It may be due to lower BMI in the present study.

\section{COPD Vs Serum HDL}

Sin and Man et al demonstrated that there were no significant differences in the HDL concentrations among the groups. Canan Radavus et al demonstrated HDL-C levels are decreasing with increasing severity of COPD. ${ }^{11}$ Our study population had low levels of HDL-C, which were decreasing with increasing of severity of COPD. 


\section{COPD Vs Atherogenic Risk}

Study by Canan Radavus et al demonstrated that LDL/HDL ratio is gradually decreasing with increasing of severity of COPD. ${ }^{11}$ But in our study, LDL/HDL which acts as indicators of atherogenic risk are gradually increasing with increasing of severity of COPD. This study showing $\mathrm{CH} / \mathrm{HDL}$ ratio is gradually decreasing with severity of COPD with no other comparable data from other studies.

\section{Smoking Status Vs Lipid Profile}

A. Venkatesan et al demonstrated increased LDL cholesterol and normal HDL cholesterol levels in smokers. ${ }^{12}$ But in our study population, all smokers are having normal levels of LDL cholesterol and low levels of HDL cholesterol. Other lipid parameters are within limits. Smoking status vs serum cholesterol, HDL, LDL and Triglycerides.

Meenakshisundaram et al showed that among the smokers TC, Triglycerides and LDL were elevated significantly than control $(\mathrm{P}<0.05)$. HDL was not statistically reduced in mild and moderate smokers. Similarly, LDL was significantly increased among all groups of smokers $(\mathrm{P}<$ 0.05). Concordant increase of LDL and decrease of HDL were noticed among smokers $(\mathrm{P}<0.05)$. The abnormalities of lipid profile were more significant when smoking pack years increased. ${ }^{13}$ In our study population $\mathrm{CH}$, LDL and TG were within normal limits irrespective of smoking status. But HDL levels are gradually decreasing with increasing of smoking pack years.

Tilwani $\mathrm{RK}^{14}$ and his associates who studied total cholesterol, triglycerides, LDL, VLDL and HDL and found that TG, LDL, VLDL and TC were significantly high in smokers when compared to non-smokers. Increasing progressively from light to heavy smokers showed direct relationship and an inverse dose relationship was found with HDL in smokers, which is comparable to that of present study. A study of Khurana $\mathrm{M}^{15}$ on lipid profile in cigarette smoker and tobacco chewers showed lower HDL cholesterol in both the groups as compared to non-smokers, which is similar to the present study.

Rastogi $\mathrm{R}^{9}$ reported that mean value of total cholesterol, LDL, VLDL and triglycerides were high in all groups of smokers, but rise was more in heavy smokers and persons smoked for more than 20 years. The mean value of serum HDL cholesterol was lower in all age groups of smokers as compared to non-smokers. The change in the mean level was maximum in heavy smokers.

The present study is consistent with the above study.

\section{CONCLUSION}

1. Smoking is an important risk factor for COPD as well as dyslipidaemia. There was no significant correlation between severity of airflow obstruction and dyslipidaemia.

2. Severity of COPD does not have correlation with Lipid changes, but all COPD patients have low levels of HDL.

3. Atherogenic risk (CH/ HDL, LDL/ HDL) is increasing with increasing of severity of COPD, which is of no statistical significance.

4. Atherogenic risk (CH/ HDL, LDL/ HDL) is increasing with increasing of smoking in terms of pack years and it is statistically significant.
5. The alteration of lipid profile in smokers have raised serious medical concern with respect to Atherogenic risk and recommendation for counselling the smokers to quit smoking and routine evaluation of serum lipid profile has been suggested.

\section{REFERENCES}

[1] Kim V, Crapo J, Zhao H, et al. Comparison between an alternative and the classic definition of chronic bronchitis in COPDGene. Annals of the American Thoracic Society 2015;12(3):332-9.

[2] Broaddus VC, Mason RJ, Ernst JD, et al. Murray \& nadel's textbook of respiratory medicine. $4^{\text {th }}$ edn. Elsevier 2015:P 317.

[3] Global strategy for the diagnosis, management, and prevention of chronic obstructive pulmonary disease 2017.

[4] Aggarwal AN, Chaudhry K, Chhabra SK, et al. Prevalence and risk factors for bronchial asthma in Indian adults: a multicentre study. Indian J Chest Dis Allied Sci 2006;48(1):13-22.

[5] Celli BR, MacNee W. Standards for the diagnosis and treatment of patients with COPD: a summary of the ATS/ERS position paper. Eur Respir J 2004;23(6):932-46.

[6] Astrup P, Kjeldsen K. Carbon monoxide, smoking \& atherosclerosis. Med Clin North Am 1974;58(2):32350.

[7] Bonna KH, Thell DS. Association between blood pressure and serum lipid in a population. Circulation 1991;83:1305-14.

[8] Dirkje PS, Huib KAM. Epidemiology and natural history of chronic obstructive pulmonary disease. In: John GG, Duncan GM, Ulrich C, et al. (eds). Respiratory medicine. $3^{\text {rd }}$ edn. Saunders 2003:1109-20.

[9] Rastogi R, Srivastava SS, Mehrotra TN, et al. Lipid profile in smokers. JAPI 1989;37(12):764-7.

[10] Sin DD, Man SFP. Why are patients with chronic obstructive pulmonary disease at increased risk of cardiovascular diseases? The potential role of systemic inflammation in chronic obstructive pulmonary disease. Circulation 2003;107(11):1514-9.

[11] Radavus C, Sunay D, Çaylan A. Evaluation of serum lipid levels in chronic obstructive pulmonary disease. Tur Toraks Der 2010;11:55-61.

[12] Venkatesan A, Hemalatha A, Bobby Z, et al. Effect of smoking on lipid profile and lipid peroxidation in normal subjects. Indian J Physiol Pharmacol 2006;50(3):273-8.

[13] Meenakshisundaram R, Rajendiran C, Thirumalaikolundusubramanian $\mathrm{P}$, et al. Lipid and lipoprotein profiles among middle aged male smokers: a study from southern India. Tobacco Induced Diseases 2010;8(1):11.

[14] Mjos DO. Lipid effects of smoking. Am Heart J 1998;115(1 Pt 2):272-5.

[15] Khurana M, Sharma D, Khandelwal PD. Lipid profile in smokers and tobacco chewers--a comparative study. J Assoc Physicians India 2000;48(9):895-7. 